\title{
FORMAÇÃO DE PROFESSORES DE LÍNGUAS
}

PARA CRIANÇAS: UM OLHAR SOBRE AS

ABORDAGENS DE ENSINO

\section{La formazione di chi insegna le lingue ai bambini: uno sguardo agli approcci didattici \\ Language teacher training for children: a look at teaching approaches}

\author{
Bianca Silva Semeguin * \\ Camila Amatuzzi Rebello** \\ Paula Garcia De Freitas* * *
}

RESUMO: O presente estudo visa a refletir sobre a formação de professores de línguas estrangeiras da atualidade para crianças, tema ainda pouco explorado. Os dados aqui apresentados são respostas dos cursistas, professores de línguas em formação inicial e continuada, às atividades do minicurso criado pelas bolsistas do Programa Licenciar da Universidade Federal do Paraná, intitulado "Abordagens de ensino de língua estrangeira para crianças", que tratou de três abordagens de ensino: a Abordagem Estruturalista, a Abordagem Intercultural e a Abordagem por Tarefas, sendo as duas últimas aquelas que norteiam as ações do projeto. O objetivo deste artigo é avaliar a familiaridade dos cursistas com as abordagens de ensino apresentadas a partir da análise quantitativa e qualitativa dos dados obtidos. Os resultados apontam para a prevalência de uma visão estruturalista de aprendizagem, de língua e de ensino entre os sujeitos da amostra, além de sugerir que novas práticas de ensino precisariam ser estabelecidas com o intuito de viabilizar a formação prático-reflexiva (ROLDÃO, 2017) de professores (de línguas estrangeiras).

PALAVRAS-CHAVE: Formação de professores; Abordagens de ensino; Línguas estrangeiras.

ABSTRACT: Il presente studio si propone di analizzare la formazione di coloro

*Graduanda em Letras - Universidade Federal do Paraná

semeguinibianca@gmail.com (ORCID: 0000-0003-3839-3260)

**Graduanda em Letras - Universidade Federal do Paraná

ca.amatuzzi@gmail.com (ORCID: 0000-0001-5190-3347)

***Docente - Universidade Federal do Paraná

paulag_freitas@ufpr.br (ORCID: 0000-0001-6121-8220)

DOI: http://dx.doi.org/10.11606/issn.2238-8281.v0i42p06-22

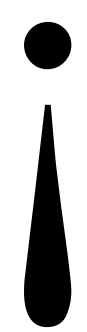


che insegnano le lingue straniere ai bambini ai nostri giorni, argomento ancora poco esplorato. I dati qui presentati sono le risposte dei corsisti, docenti di lingue straniere in formazione iniziale o in aggiornamento, alle attività del minicorso "Approcci all'insegnamento di lingua straniera ai bambini" creato dalle borsiste del Programma Licenciar dall'Università Federale del Paraná, il cui argomento sono stati tre approcci di insegnamento: l'approccio strutturalista, l'approccio interculturale e l'approccio Task-Based Language Teaching (TBLT), tenendo conto che gli ultimi due sono quelli che guidano le azioni del progetto. L'obiettivo di questo articolo è quello di valutare la familiarità dei corsisti con gli approcci di insegnamento presentati attraverso l'analisi quantitativa e qualitativa dei dati ottenuti. I risultati rivelano la prevalenza di una visione strutturalista di apprendimento, di lingua e di insegnamento tra i soggetti del campione, oltre a suggerire che dovrebbero essere incentivate nuove pratiche di insegnamento per rendere possibile la formazione pratica e riflessiva (ROLDÃO, 2017) di insegnanti (di lingue straniere).

PAROLE CHIAVE: Formazione di insegnanti; Approcci all'insegnamento; Lingue straniere.

ABSTRACT: The present study aims to reflect on the training of teachers of foreign languages for children, a subject that is still little explored. The data presented here are responses of the course-participants, language teachers in initial and continuing education, to the activities of the mini-course created by the Program Licenciar at the Federal University of Paraná entitled "Approaches to foreign language teaching for children", which dealt with three teaching approaches: the Structuralist Approach, the Intercultural Approach and the Task-based Approach, the last two being those that guide the actions of the project. The objective of this article is to evaluate the familiarity of course participants with the teaching approaches through a quantitative and qualitative analysis of the data obtained. The results point to the prevalence of a structuralist view of learning, language and teaching among the subjects of the sample, in addition to suggesting that new teaching practices would need to be established in order to enable (foreign language) teachers' practical and reflective education (ROLDÃO, 2017).

KEYWORDS: Teacher training; Teaching approaches; Foreign languages. 


\section{Introdução}

Por conta da COVID-19, em 2020 fomos, todos, desafiados a (re)pensar nossa conduta como indivíduos, cidadãos, profissionais da educação e, especificamente no nosso caso, como professores de língua italiana dentro do projeto "Intercultura nas escolas: o italiano como língua e cultura na rede pública de ensino", vinculado ao Licenciar, um programa institucional cujo objetivo é apoiar as Licenciaturas da instituição por meio da oferta de bolsas aos alunos, da orientação dos coordenadores e do acompanhamento pedagógico dos projetos.

Há mais de uma década o projeto do Italiano é proposto anualmente ao programa com o objetivo de proporcionar aos alunos do curso de Letras-Italiano a partir do $2 .^{\circ}$ ano do curso uma formação inicial de professores de línguas alinhada com o que García (1999, p. 99) chamou de "conhecimento didático do conteúdo", isto é, um conhecimento do que ensinar, que se adquire à medida em que se compreende o que se aplica.

Para tanto, seguimos um percurso de formação de cinco etapas apoiado na Abordagem por Tarefas (NUNAN, 2004), quais sejam: 1) Tarefas para o ensino da teoria; 2) Planejamento do curso de italiano para crianças; 3) Preparação das tarefas para as crianças; 4) Aplicação das tarefas com as crianças e 5) Registro e divulgação dos resultados. Descrito em outros artigos (FREITAS, 2020; FREITAS, 2019), esse percurso tem se mostrado eficaz para o desenvolvimento da competência comunicativa na LE, e, principalmente, pedagógica dos bolsistas, que compreendem, em um ano de atividades, qual é o papel do professor da atualidade: o de orientar o processo de (auto)aprendizagem, provocar a reflexão e, acima de tudo, proporcionar vivências que façam com que a (auto)educação aconteça (ROLDÃO, 2017).

Em 2020, porém, em meio à pandemia, tivemos que rever as cinco etapas do percurso de formação. Não pudemos, por exemplo, planejar, preparar e aplicar as tarefas para o ensino intercultural de italiano previstas nas fases 2,3 e 4 do percurso, que aconteceriam durante as 30 horas de oficinas de sensibilização à língua e à cultura italiana que normalmente oferecemos a alunos de $3 .^{\circ}$ e $4 .^{\circ}$ ano de escolas municipais de período integral de Curitiba. Outro desafio foi adaptar as tarefas para o ensino da teoria da fase 1 do percurso para o ensino remoto. Uma disciplina optativa de 60 horas foi oferecida nesse formato nos meses de julho e agosto de 2020 para alunos dos cursos de Letras com excelentes resultados. No entanto, verificou-se que os alunos matriculados, em sua maioria calouros de outras línguas, não poderiam atender as demandas de um possível ensino on-line de italiano para crianças, caso viessem a ser bolsistas do projeto. Diante de tal conjuntura, e considerando que os bolsistas podem participar do projeto por dois anos consecutivos, foram selecionadas três das quatro alunas que haviam participado do projeto em 2019, que se dedicaram, em 2020, inteiramente à fase 5 do percurso, criando atividades formativas para o "registro e divulgação dos resultados" do ano anterior, quando haviam tido a oportunidade de trabalhar o tema "as profissões de Leonardo Da Vinci" com as crianças.

A fase 5 do ciclo de tarefas para a formação (inicial) de professores perpassa todas as outras etapas e visa à análise e à reflexão do que foi vivenciado e/ou produzido ao longo do projeto. 
Pode acontecer imediatamente após realizar uma atividade ou uma fase, ou, ainda, ao final de todo percurso e abarca a realização de outras tarefas, como diários reflexivos, materiais de ensino, cursos voltados a professores de LE, participação em eventos e redação de artigos (FREITAS, 2020, p. 70).

Temos notado que a fase 5 do percurso tem efeitos interessantes sobre os bolsistas e também sobre aqueles que participam das ações idealizadas por eles. Do lado de cá, os bolsistas sentem ter algo a acrescentar na formação dos profissionais; do outro lado, professores já experientes, bem como professores em formação veem suas práticas valorizadas pela universidade. Com experiências desse tipo, os bolsistas parecem internalizar ainda mais a teoria por precisarem expô-la aos colegas que, por sua vez, dão indícios de se inspirarem nas práticas de seus colegas.

Por tudo isso, ao longo dos oito meses de vigência das bolsas de 2020, a equipe se viu motivada a realizar as seguintes tarefas de registro e divulgação dos resultados: a) dois cursos de extensão, sendo o primeiro de 15 horas intitulado "Abordagens de ensino de LE para crianças", e o segundo, de 8 horas, com o título "Atividades para o ensino de línguas para crianças"; b) uma live, intitulada "Construindo as pontes de Leonardo Da Vinci", com a participação dos alunos do Programa de Educação Tutorial (PET) Madeira Mágica para contar o impacto da parceria de 2019 na sua formação enquanto alunos dos cursos de Letras-italiano e Engenharia Industrial e Madeireira da Universidade Federal do Paraná; c) a participação no curso de extensão Tópicos sobre ensino/ aprendizagem da língua italiana coordenado pela Prof. ${ }^{a}$ Dr. ${ }^{a}$ Paula Garcia de Freitas; e d) a criação de seis vídeos, sendo dois deles dedicados às abordagens de ensino privilegiadas no projeto, a abordagem intercultural e a abordagem por tarefas, um vídeo em comemoração aos 10 anos do projeto, em que ex-bolsistas contaram como a sua participação no projeto impactou na sua formação e três vídeos para contar a história de Leonardo da Vinci a partir de trechos da obra Leo de Luisa Mattia, Alberto Nucci Angeli e Lorenzo Terranera (Edizioni Lapis, 2017).

Ressalta-se que, embora todas as atividades realizadas possam ser enquadradas na fase 5 do percurso, algumas delas privilegiaram a divulgação da teoria e a reflexão sobre seus princípios, outras tiveram o objetivo de confrontar teoria e prática, como geralmente fazemos na fase 1; outras visaram a revelar os impactos do projeto na formação dos alunos que dele participam e outras, por fim, foram direcionadas às crianças e fecharam o ciclo de tarefas dedicado a Leonardo Da Vinci, cujo objetivo (intercultural) foi apresentar o artista às crianças, falar de suas facetas e, principalmente, mostrar que ele foi "gente como a gente", com problemas familiares, de aprendizagem e de (auto)aceitação (FREITAS, 2020, p. 77), como fazemos nas fases 2, 3 e 4. Todo o material audiovisual produzido pela equipe e elencado no parágrafo anterior pode ser visualizado no canal do projeto no YouTube, Licenciar Italiano (https://www.youtube.com/ channel/UCOk13iOvfXYMMBnjA_q06sA).

Diante de tantas atividades, neste artigo optamos por descrever e avaliar de forma qualitativa e quantitativa os impactos do curso de extensão "Abordagens de ensino para crianças" de 15 horas sobre as bolsistas e sobre os cursistas, professores de línguas em formação inicial e continuada. $\mathrm{O}$ curso foi elaborado pelas bolsistas com o objetivo de apresentar a teoria que 
orienta as ações do projeto, a saber, como já mencionado, a Abordagem Intercultural (LIDDICOAT; SCARINO, 2013; LIDDICOAT et al., 2003) e a Abordagem por Tarefas (NUNAN, 2004; WILLIS, 2003). Com atividades síncronas e assíncronas, o curso foi idealizado para que alunos de Letras e professores de línguas conhecessem as abordagens que orientam as ações do projeto e vislumbrassem os seus efeitos no ensino de línguas para crianças.

A criação desse curso para professores em formação justifica-se por percebermos que embora a Abordagem Intercultural e a por Tarefas estejam ganhando cada vez mais adeptos em todo o mundo (EAST, 2012; ELLIS, 2015; SAMUDA; BYGATE, 2008; VAN DEN BRANDEN, 2006; LIDDICOAT; SCARINO, 2013; LIDDICOAT et al., 2003; LANDULFO; BARROS, 2017), no Brasil elas parecem ser ainda pouco difundidas entre os professores de línguas.

De fato, as respostas dos cursistas às atividades propostas no curso apontam ainda para a preferência por abordagens mais tradicionais de ensino entre os professores de línguas, mesmo diante do discurso em prol de abordagens centradas no aluno, como podem ser consideradas aquelas adotadas no projeto.

Diante dessa constatação, neste artigo procuramos avaliar, quantitativa e qualitativamente, a familiaridade dos cursistas com as abordagens apresentadas no curso, por meio da observação do modo como responderam às atividades propostas.

O artigo está assim estruturado: após esta introdução, há uma seção dedicada às teorias que embasam as ações do projeto, a Abordagem Intercultural e a Abordagem por Tarefas; na seção Metodologia, descrevemos como o curso de extensão foi estruturado e como foi feita a análise dos dados; segue uma seção dedicada à análise dos dados e, por fim, a conclusão.

\section{Pressupostos teóricos}

Em um texto de 1998, Amiguinho já atentava para a "necessidade de gerar ambientes fortemente interativos desde o início da formação dos professores" (p. 40) que garantissem a prática profissional aos alunos e a compreensão e produção de saberes e competências com o seguinte propósito: fazer dos futuros professores profissionais prático-reflexivos, ou seja, profissionais que refletem sobre a (própria) prática.

É isso que procuramos proporcionar no projeto "Intercultura nas escolas: o italiano como língua e cultura na rede pública de ensino", adotando a Abordagem por Tarefas (NUNAN, 2004), uma abordagem de ensino de LE, também na formação dos futuros professores de italiano. Considerada por muitos autores como a versão forte da Abordagem Comunicativa (ELLIS, 2006; HOLLIDAY, 1994), a Abordagem por Tarefas vê na própria tarefa a razão para executar coisas com a LE (ELLIS, 2006, p. 68).

Nesse sentido, fazer um avião de dobradura, inventar um dispositivo para economizar água, dar instruções sobre um jogo ou mesmo preparar e dar aulas de italiano podem ser consideradas tarefas a serem propostas a alunos de LE. Em todas essas atividades, embora o objetivo principal dos alunos seja alcançar o resultado da tarefa, o do professor pode ser o de ajudar a melhorar 
sua capacidade em dar instruções claras na LE, e, assim, auxiliar no desenvolvimento da competência comunicativa desses alunos. No caso do projeto do italiano no Programa Licenciar, além do desenvolvimento linguístico, estimula-se também o da competência pedagógica dos bolsistas, alunos do curso de Letras-italiano, já que, durante todo o percurso, são convidados a realizar tarefas habituais do professor de LE ou do profissional de Letras.

Pode-se dizer que um dos princípios da Abordagem de Ensino por Tarefas seja a experiência e o uso contextualizado e autêntico da LE para alcançar um resultado (não necessariamente linguístico) previsto pela tarefa (VAN DEN BRANDEN, 2016). O aluno é, então, estimulado e impulsionado pela interação, a "aprender fazendo", e enxergar no professor "um líder, um organizador de atividades, um gestor que conduz o grupo para alcançar os objetivos da tarefa. E isso é muito mais do que ser um transmissor de conhecimento" (MOTLAGH et al., 2014, p. 09, tradução nossa) ${ }^{1}$, como preconizam abordagens mais estruturalistas de ensino, ainda tão comuns nas aulas e na formação de professores (ROLDÃO, 2017). Vale lembrar que, na visão estruturalista de ensino de LE, ensinar significa apresentar conhecimentos linguísticos aos alunos que, por sua vez, serão convidados a empregar corretamente tais conhecimentos em exercícios que têm por objetivo "a internalização de formas linguísticas, a memorização de modelos dados, sem a intervenção do aluno no processo ou nos conteúdos oferecidos" (MAIA et al., 2002, p. 45).

A adoção da Abordagem por Tarefas na formação de professores pode ser um modo de aproximar o futuro professor de abordagens de ensino de LE com um viés mais relacional, dialógico, cultural e contextual, como sugerem Imbernón e Colén (2014). Incentivar esses futuros professores a adotar tal abordagem nas Oficinas de sensibilização à língua e à cultura italiana é também uma maneira de ajudá-los a se familiarizar com ela, uma abordagem de ensino cuja maestria é difícil de ser adquirida de modo independente, automático e imediato (NORRIS, 2015).

O projeto "Intercultura nas escolas: o italiano como língua e cultura na rede pública de ensino", como o próprio nome indica, visa o desenvolvimento da competência intercultural das crianças que frequentam as oficinas e, para isso, o professor-bolsista precisa ser capaz de refletir sobre a visão de ensino-aprendizagem que se almeja. Como postulam Liddicoat e Scarino (2013), aprender uma língua dentro de uma perspectiva intercultural requer a compreensão de que língua é sistema e também prática social, um processo recíproco de interpretação da linguagem e dos indivíduos que a usam. Nesse sentido, língua e cultura estão intimamente ligadas, sendo esta última interpretada como "as manifestações e práticas artísticas e sociais de um grupo, mas também a lente por meio da qual as pessoas interpretam e comunicam significados mutuamente" (p. 46). Trata-se de um processo de "tomada de consciência" do que já se sabe e do que está sendo adquirido e a sala de aula de LE seria, então, o espaço para que os próprios alunos desenvolvam a capacidade de interpretar o próprio mundo através da própria língua e da própria cultura, segundo esses autores.

$\overline{1}$ No original: "[However, there are several other roles associated with a TBLT teacher. Such] a teacher is mostly a leader and organizer of tasks and class management in order to lead the whole class towards the objectives of tasks. This is much more than being merely a supplier of knowledge." (MOTLAGH et al., 2014, p.9) 
Considerando que é possível adotar a abordagem por tarefas que preveja também uma aprendizagem intercultural (FREITAS, 2019), no curso criado pelas bolsistas para a divulgação das teorias de ensino que orientam as ações do projeto, visou-se a relacionar tais abordagens e identificar as principais técnicas de cada uma delas, estrutural, intercultural ou por tarefas. $\mathrm{O}$ curso foi a fonte dos dados analisados neste artigo sobre o conhecimento dos cursistas acerca dessas abordagens e das práticas que poderiam adotar em suas aulas.

\section{Metodologia}

\subsection{Contexto da pesquisa}

Como já dissemos, os dados que apresentamos neste artigo são oriundos do curso "Abordagens de ensino de LE para crianças" ministrado pelas três bolsistas do italiano de 2020 junto ao Programa Licenciar da UFPR - Ana Paula Brun, Bianca Silva Semeguini e Camila Amatuzzi Rebello, duas delas autoras deste artigo - sob a coordenação da professora Paula Garcia de Freitas, que também assina este texto. O curso foi idealizado para cumprir horas de "atividades formativas", como previsto em edital, divulgar as ações do projeto para alunos dos cursos de Letras e professores que se interessam pelo ensino de línguas para crianças e, principalmente, proporcionar momentos de reflexão sobre a prática pedagógica para as bolsistas, um dos objetivos da fase cinco do percurso de formação que adotamos nesse projeto, descrito por Freitas em outros textos $(2020 ; 2019)$.

O curso, com carga horária total de 15 horas, aconteceu entre os dias 3 e 7 de agosto de 2020, contando com três encontros síncronos e três atividades assíncronas. O objetivo foi apresentar três abordagens de ensino: a estruturalista, a intercultural e a por tarefas e colocá-las em relação por meio de diferentes atividades. A ideia era que ao final do curso, o cursista fosse capaz de compreender como tais abordagens poderiam acontecer em sala de aula e avaliar quais seriam seus impactos, com base no tipo de atividade "típica" de cada uma delas.

Os encontros síncronos, com duração de duas horas, aconteceram em dias alternados, na segunda-feira, na quarta-feira e na sexta-feira, em reuniões virtuais na Plataforma Google Meet e visaram a criar um momento de troca entre os inscritos e as bolsistas, em que todos fossem capazes de relacionar suas experiências como professores e alunos de línguas estrangeiras com as três abordagens apresentadas no curso, aprimorando, assim, seu conhecimento sobre como poderiam ser realizadas em sala de aula. Já as atividades assíncronas começaram alguns dias antes, com atividades disponibilizadas na Plataforma Google Classroom. O cronograma (Tabela 1) a seguir resume as principais informações do curso (datas, tipo de atividade, conteúdos). 
Tabela 1 - Cronograma de atividades.

\begin{tabular}{|l|l|l|}
\hline DIA & $\begin{array}{c}\text { TIPO DE } \\
\text { ATIVIDADE }\end{array}$ & \multicolumn{1}{c|}{ CONTEÚDOS } \\
\hline $30 / 07$ & assíncrona & $\begin{array}{l}\text { Observação de uma atividade típica da abordagem estruturalista } \\
\text { para reflexão sobre como ela se dá em sala de aula. }\end{array}$ \\
\hline $03 / 08$ & síncrona & $\begin{array}{l}\text { Apresentação do curso; Conceito de Abordagem; Abordagem Es- } \\
\text { truturalista e conceitos de língua, ensino e aprendizagem inerentes } \\
\text { a ela; atividades típicas dessa abordagem. }\end{array}$ \\
\hline $04 / 08$ & assíncrona & $\begin{array}{l}\text { Análise de uma atividade típica da Abordagem por Tarefas a partir } \\
\text { da teoria apresentada por meio de um vídeo e de um texto teórico. }\end{array}$ \\
\hline $05 / 08$ & síncrona & $\begin{array}{l}\text { Discussão sobre o papel do professor na era Pós-método; Aborda- } \\
\text { gem por Tarefas e conceitos de língua, ensino e aprendizagem ine- } \\
\text { rentes a ela; Conceitos e características da Tarefa Comunicativa; } \\
\text { atividades típicas dessa abordagem. }\end{array}$ \\
\hline $05 / 08$ & assíncrona & $\begin{array}{l}\text { Análise de uma atividade que promove aprendizagem intercultural a } \\
\text { partir da teoria apresentada por meio de um vídeo e de um texto teórico. }\end{array}$ \\
\hline $07 / 08$ & síncrona & $\begin{array}{l}\text { Discussão sobre maneiras de se entender Cultura; Apresentação } \\
\text { da Abordagem Intercultural escolhida para o projeto e conceitos } \\
\text { de língua, ensino e aprendizagem inerentes a ela; Cinco princípios } \\
\text { para a aprendizagem intercultural de uma LE (LIDDICOAT et al.. } \\
\text { 2003); atividades típicas dessa abordagem. }\end{array}$ \\
\hline
\end{tabular}

Fonte: as autoras.

A primeira atividade assíncrona apresentava um exercício estruturalista, bastante comum nas aulas de línguas: um texto sobre Leonardo da Vinci repleto de lacunas para serem completadas com o verbo sugerido na conjugação correta. Tratava-se de uma atividade de "preenchimento de lacunas", proposta por muitos professores que veem nela uma possibilidade de engajar os alunos na prática de estruturas previamente selecionadas em um "contexto comunicativo", como pode ser considerado o texto sobre Da Vinci.

Aos cursistas, foram feitas perguntas a fim de averiguar a utilização ou não desse tipo de exercício nas aulas de língua e de incitar uma reflexão sobre os benefícios da abordagem e sobre sua extensa propagação no meio escolar, bem como sobre seus resultados no processo de ensino-aprendizagem.

No primeiro encontro síncrono, fizemos uma breve explicação sobre o caminho a ser percorrido no curso e iniciamos nossa conversa falando sobre o conceito de abordagem e sua relação com a prática pedagógica do professor. Depois, tratamos as características da Abordagem Estruturalista e os conceitos de língua, ensino e aprendizagem nessa perspectiva e suas 
atividades tradicionais. Separamos alguns trechos das respostas que recebemos na atividade assíncrona para interagir com os cursistas. Para concluir, sintetizamos a nossa fala e as novas respostas que recebemos quando explicitamos as características do método de ensino de estruturas APP (Apresentação-Prática-Produção) ${ }^{2}$.

Na segunda atividade assíncrona, foram propostos dois meios de apresentação da teoria: um vídeo, produzido pelas próprias bolsistas, e um texto sobre a Abordagem por Tarefas (XAVIER, 2012, p. 52-59), e propusemos a análise de uma atividade elaborada por nós que fora utilizada com as crianças no ano anterior. A atividade estava dividida em 3 partes: na primeira, propunha-se o jogo "perfil das profissões", em que os alunos recebiam dicas do professor na LE, até que alguém adivinhasse de qual profissão se tratava. O jogo continha 7 profissões, com 4 dicas para cada uma, que informavam as habilidades daquele profissional ou os objetos utilizados por ele em sua rotina de trabalho. Depois que todas as profissões fossem descobertas, o professor perguntava se uma única pessoa conseguiria fazer todos esses trabalhos. Então, para apresentar o polímata Leonardo Da Vinci, mostrava-se uma foto dele, uma imagem referente a cada um de seus trabalhos e pedia-se para os alunos associarem a imagem a uma das profissões do jogo. A segunda parte consistia em uma breve contação de história, também na LE, sobre a trajetória de vida de Da Vinci. Na terceira parte, os alunos faziam um desenho da profissão que tinham achado mais divertida e deviam explicar por quê.

Os cursistas, com base no vídeo introdutório e na leitura do texto teórico, deveriam responder "cite 3 características que fazem dessa atividade uma tarefa comunicativa", com o objetivo de estimulá-los a perceber os elementos e princípios que fundamentam a tarefa comunicativa.

No segundo encontro síncrono, iniciamos com um panorama da era Pós-Método, o papel do professor e as 10 macroestratégias de Kumaravadivelu (1994), seguido das características da Abordagem por Tarefas (NUNAN, 2004) e os conceitos de língua, ensino e aprendizagem atrelados a ela. Para concluir o encontro, resgatamos a atividade assíncrona para elucidar, em conjunto, os elementos que faziam dela uma tarefa comunicativa, relacionando o conteúdo do vídeo, do texto e as novas informações.

Para a terceira atividade assíncrona, propusemos novamente a análise de uma atividade realizada com as crianças que participaram da oficina no ano anterior. Para a análise, os cursistas tinham, mais uma vez, como recursos, um vídeo criado pelas bolsistas e um texto teórico (LIDDICOAT et al., 2003), dessa vez sobre a Abordagem Intercultural.

A atividade a ser analisada estava dividida em duas etapas: na primeira, os grupos de crianças recebiam peças de um quebra-cabeça, que continham, no verso, pistas sobre a profissão. Elas deveriam relacionar palavras e imagem a uma das profissões escritas na lousa e depois apresentar aos colegas, a partir das pistas, a profissão da imagem. A cada apresentação, os alunos eram questionados se aquela era uma profissão do passado, do presente ou do futuro. $\mathrm{Na}$

2 O procedimento metodológico APP consiste na "Apresentação" de uma estrutura/função ao aluno, na sua "Prática" por meio de exercícios guiados e na sua "Produção", momento em que a estrutura é colocada em uso comunicativo (HARMER, 2009). 
segunda parte, o professor sorteava uma pergunta que continha uma habilidade de cada uma das profissões e os alunos deveriam adivinhar qual era a profissão. Esperava-se que, nesse momento, eles fossem capazes de justificar as respostas com as palavras do quebra-cabeça.

Por meio dessa atividade, os cursistas deveriam responder "Com base no texto e no vídeo, cite 3 características que fazem dessa atividade uma atividade Intercultural". O objetivo era incentivá-los a compreender os fundamentos de uma tarefa intercultural.

O terceiro encontro síncrono começou com a apresentação de definições do termo cultura de acordo com diferentes perspectivas. Em seguida, apresentaram-se os princípios da Abordagem Intercultural e as definições de língua, ensino e aprendizagem inerentes a ela, com base em Landulfo e Barros (2017) e Liddicoat et al. (2003), esses últimos também autores dos cinco princípios para a aprendizagem intercultural de uma LE tratados naquele encontro. Nesse sentido, procuramos colocar em evidência diferentes maneiras de se entender cultura na sala de aula, como propõe Fontes (2002), e enaltecer a noção de "conhecer a si mesmo conhecendo o outro" proposta pela autora e adotada no projeto. Para finalizar, retomou-se a última atividade assíncrona para discutir a noção de Intercultura, mas também de Tarefa e tudo o que havia sido tratado no curso.

\subsection{Coleta e análise dos dados}

Neste artigo, procuramos identificar, por meio das respostas dos cursistas, se eles teriam familiaridade com as diferentes abordagens apresentadas ao longo do curso. Para isso, foram analisadas as respostas das atividades assíncronas dadas por eles no Google Classroom.

Inscreveram-se no curso 46 alunos de perfil heterogêneo: professores de línguas formados em Letras, professores de línguas com outro tipo de formação, graduandos em Letras e interessados em geral, conforme informações colhidas no formulário de inscrição. No entanto, foram base para a análise dos dados as respostas de 27 cursistas, que frequentaram todos os encontros e responderam ao menos a duas atividades assíncronas. Tais cursistas possuíam níveis diferentes de educação: dentre eles, 10 ainda cursavam a graduação; 4 já haviam se formado; 3 possuíam pós-graduação lato sensu completa e 1 incompleta; 2 estavam na pós-graduação stricto sensu; 3 já haviam concluído a pós-graduação stricto sensu (nível mestrado); e 4 já haviam concluído a pós-graduação stricto sensu (nível doutorado).

As respostas válidas foram compiladas em uma tabela Excel e delas foram selecionados os trechos que respondiam à pergunta que orienta este artigo, isto é, qual o grau de familiaridade dos cursistas com as abordagens tratadas no curso, cujo teor será analisado a seguir.

\section{Análise dos dados}

Nesta seção, serão descritos e analisados os dados de 27 cursistas, indicados com a letra "A", seguida do número de cada participante na tabela (A1, A2, etc.), considerando os que responderam a pelo menos duas das atividades assíncronas do Google Classroom.

A primeira atividade, que visava a colocar luz sobre a Abordagem Estruturalista, era com- 
posta por três perguntas: "Você já fez ou utilizou esse tipo de exercício? Após realizar essa atividade, o que o aluno aprendeu? Qual foi o ensinamento linguístico desse exercício? Na sua opinião, por que esses exercícios são usados com tanta frequência?”. O primeiro fator a ser analisado é que essa atividade foi a única respondida por todos os cursistas. Isso pode ser uma evidência da forte presença desse tipo de abordagem na formação deles, tanto como alunos quanto como professores de línguas.

Para melhor compreensão dos fenômenos, as três perguntas dessa atividade foram desmembradas. A primeira parte, que indagava sobre a utilização de exercícios de preenchimento de lacunas, foi respondida pela maioria dos cursistas de maneira afirmativa, reforçando a grande familiaridade com a abordagem. Vejamos algumas respostas:

A18: Eu já fiz esses exercícios como aluna de LE e já apliquei como professora.

A21: Durante alguns cursos de línguas que frequentei era comum se utilizar atividades desse tipo.

Respostas como a de A18, indicando que já realizaram a atividade como alunos e a aplicam regularmente como professores, foram dadas por 10 dos 27 cursistas (aproximadamente 37\%). Respostas como a de A21, que apresenta apenas relatos do ponto de vista de aluno, foram dadas por 6 dos 27 cursistas (aproximadamente 22\%). Respostas de outras naturezas (tais como faixa etária do público-alvo ou relação entre atividade e livro didático) foram dadas por 11 dos 27 cursistas (aproximadamente $40 \%$ ) e serão comentadas posteriormente.

A segunda parte da pergunta da primeira atividade também foi respondida por todos os participantes que indicaram que o objetivo principal desse tipo de atividade é o foco na estrutura (FonFs - LONG; ROBINSON, 1998) para a "consciência linguística" (A1) ou "sistematização da conjugação verbal" (A2; A5; A20), conforme excertos de suas respostas:

A1: Acredito que é um exercício voltado para a consciência linguística.

A2: Aprendeu a conjugar os verbos na primeira pessoa do singular.

A5: Acredito que ajuda para aprender a gramática.

A20: São exercícios que focam na forma (na estrutura da língua), são bons para fixar conteúdos.

Respostas como a de A2, que afirmam que o ensinamento linguístico do exercício é a conjugação verbal, foram dadas por 10 dos 27 cursistas (aproximadamente 37\%). Respostas como a de A5, que indica o aprendizado da gramática como ensinamento linguístico, foram dadas por três dos 27 cursistas (aproximadamente 11\%). Respostas como a de A20, que apontam a fixação do conteúdo como ensinamento linguístico, foram dadas por cinco dos 27 cursistas 
(aproximadamente 18\%). Dois cursistas não responderam a essa pergunta especificamente. Nove respostas (aproximadamente 33\%) que divergiam muito entre si foram descartadas dessa contagem.

A26 resume as respostas ao afirmar:

Ao meu ver, eles ajudam a sistematizar as regras gramaticais e ajudam no entendimento dos elementos que compõem o funcionamento de uma língua, ajudando-nos a vê-la, a imaginá-la melhor em sua forma. (...) É a língua em sua estrutura: pura e crua, concreta.

A terceira parte da primeira atividade questionava os motivos que justificassem a frequência de uso do exercício proposto. Essa pergunta foi a que apresentou maior diversidade de respostas, pois cada um dos cursistas deu uma justificativa única. Isso pode indicar que se trata de um conhecimento empírico. A maior incidência (4 dos 27 cursistas, aproximadamente 14\%) aponta como justificativa para o seu uso a fácil aplicação e correção dos exercícios. Outras indicam que a fixação das estruturas requer intensa prática mecanizada ( 2 dos 27 cursistas, aproximadamente $7 \%$ ); outras ainda apontam para a prática contextualizada em textos como auxílio para o desenvolvimento também da habilidade leitora ( 2 dos 27 cursistas, aproximadamente $7 \%$ ) ou da competência reflexiva ( 2 dos 27 cursistas, aproximadamente $7 \%$ ). Eis algumas respostas:

Fácil aplicação: A9: Acredito que eles são usados como muita frequência porque são amplamente reproduzidos e porque é mais fácil a sua aplicação e correção.

Fixação das estruturas: A7: Usamos bastante para fixar e no caso deste exercício apresentado, fazer uso do verbo corretamente.

Competência reflexiva: A19: Acredito que em sala de aula devemos incitar reflexões visto que assim possibilita-se duas práticas de aprendizagem em um mesmo momento: o ensino do conteúdo e a educação para o raciocínio de ideias.

Desenvolvimento da habilidade leitora: A21: Além de ser um exercício gramatical, acaba trabalhando a parte de leitura em texto da língua.

As respostas dos demais cursistas (17, aproximadamente 62\%) apontam para diferentes justificativas. A18 admite replicar, como professora, essa tarefa, apesar de jamais ter gostado dela como aluna. Tal reconhecimento nos dá base para compreender que a experiência e as crenças sobre ensino e aprendizagem de LE ainda estão muito atreladas à Abordagem Estruturalista, na qual a língua é estrutura e a aprendizagem é avaliada pelo seu uso correto, o professor é visto como detentor do saber e o aluno como receptor passivo. É importante ressaltar que A18 possui pós-graduação completa e trabalha na área há anos; logo, esse tipo de reflexão pode ser considerado comum no seu dia a dia.

A resposta de A15, estudante de graduação, nos traz mais uma pista do porquê de os exer- 
cícios estruturalistas serem tão aplicados: estão muito presentes nos materiais didáticos. Isso reforça a teoria de que a Abordagem Estruturalista ainda está presente no dia a dia, nos livros didáticos e no imaginário de alunos e professores.

Além da praticidade de realização e fácil correção, A11 acredita que os professores usam esse tipo de exercício porque não suscitam questionamentos que vão além da estrutura gramatical, dando mais confiança para o professor iniciante, que não precisará se arriscar oralmente e não será questionado sobre a possibilidade de múltiplas respostas. A tipologia do exercício garante menor interação e demanda pouco tempo de preparo, realização e correção, tornando-se de certa forma automática, mecânica. Assim como A18, A11 também possui o título de doutorado e anos de experiência na área.

Outra condição a ser analisada sobre a aplicabilidade desse exercício é o público-alvo. $\mathrm{O}$ planejamento da aula deve considerar a faixa etária dos alunos, seus interesses e desenvolvimento cognitivo. Dentre os 27 cursistas, 4 trabalham com a educação infantil e não consideram esse tipo de atividade adequado para seus alunos. Coincidentemente, dois desses cursistas problematizaram a eficiência das atividades estruturalistas; talvez por serem condicionados, pelo seu público-alvo, a utilizar outras abordagens, tenham começado a ponderar sobre esse tipo de atividade no ensino da LE:

A3: Nunca trabalhei com este tipo de exercício, até porque meu público são crianças e não faria sentido usá-lo (...).

A5: Trabalho a língua italiana com crianças e nunca utilizei este tipo de exercício porque acredito que não seria adequado para esta faixa etária (...).

As respostas dessa primeira atividade assíncrona podem indicar que a aplicação da Abordagem Estruturalista está quase intrínseca à atividade de ensinar uma língua estrangeira, principalmente quando o público em questão é de uma faixa etária mais velha, desde adolescentes até idosos. É inegável a popularidade de atividades estruturalistas e a força expressiva da abordagem ainda na atualidade. Não é por acaso que a maioria dos cursistas afirma que já fizeram e já aplicaram atividades do gênero com o objetivo de ensinar, fixar e exercitar estruturas gramaticais. Em meio às afirmações de adesão, alguns cursistas se questionam sobre o resultado prático dessa abordagem: os problemas mais apontados nas respostas são a dificuldade de transpor tais aprendizados na fala (A4, A5, A6) e a falta de naturalidade dos enunciados (A10), que torna as situações dos exercícios muito simuladas, formando alunos dependentes de estruturas perfeitas (que não é o que se encontra na língua falada).

A atividade que precedeu o segundo encontro síncrono era relativa à Abordagem por Tarefas: os cursistas deveriam ler um texto teórico e assistir um vídeo sobre os principais pontos dessa abordagem, e apontar em um plano de aula três características que faziam daquela atividade uma tarefa comunicativa. Dessa vez, apenas 18 dos cursistas 27 responderam, aproximadamente $66 \%$. Esse pode ser o primeiro indício de que a Abordagem por Tarefas não é muito 
conhecida; logo, poucos se sentiram à vontade para falar sobre ela. Outro indício vem do fato de que mesmo os que responderam, o fizeram apenas por meio das informações obtidas pelo vídeo: diferente da pergunta anterior, ninguém trouxe relatos de experiências pessoais, nem como professor, nem como aluno:

A3: Penso que essa atividade é um exemplo de uma tarefa comunicativa porque: usa a língua para resolver uma questão proposta; promove uma intenção comunicativa ao processo de aprendizagem; cria situações em que há troca de informações; dota os alunos de um propósito para se envolverem na atividade; fornece os instrumentos necessários para que os alunos se insiram na situação; com ela os alunos têm a liberdade de utilizar toda a sua bagagem linguística e cultural; a participação do aluno impacta na sua aprendizagem e na dos colegas.

A7: 1. Apresenta situações de troca de informações; 2 . Tem intenção comunicativa; 3 . Envolve os alunos numa situação real.

A18: 1. Engajamento dos alunos (de quem descreve e de quem tenta adivinhar); 2. O uso da LE para fazer descrição de um assunto de interesse geral: profissões; 3 . Há uma busca por um resultado que está associada à compreensão de língua (vocabulário) e o desenvolvimento da habilidade oral (descrição).

A pergunta feita na atividade requeria o elenco de três características da Abordagem por Tarefas, e respostas como as de A18 foram dadas por 10 dos 18 cursistas (aproximadamente 55\% das respostas obtidas) como que seguindo um "passo a passo", através de tópicos, cada qual elencando pontualmente uma característica, apenas A20 realizou uma análise mais profunda apontando mais de três características ao relacionar teoria e prática. Não foram registradas opiniões ou experiência própria de sala de aula, seja como aluno, seja como professor; também não foram registradas características que não fossem as fornecidas pelo vídeo e texto selecionados.

A atividade assíncrona referente ao terceiro encontro tratava da Abordagem Intercultural e, assim como na segunda atividade, tinha como base teórica um vídeo e um texto. Junto à teoria, foi apresentado aos cursistas um plano de aula, no qual deveriam responder à proposta: "com base no texto e no vídeo, cite 3 características que fazem dessa atividade Intercultural ".

Assim como aconteceu com a atividade anterior, essa também não obteve tantas respostas quanto a primeira, apenas 15 dos 27 cursistas (aproximadamente 55\%) e todas seguiam o mesmo padrão: responder exclusivamente à pergunta, com poucos ou nenhum comentário, ou observações. As respostas convergem sempre para os mesmos pontos: uso ativo da língua, trabalho em grupo, reflexões ativas por parte dos alunos e conhecimento de uma cultura por meio da língua:

A3: Acredito que essa atividade é um exemplo de atividade intercultural porque foram considerados os conhecimentos prévios dos alunos; houve reflexões sobre as diferenças e semelhanças linguísticas e culturais; o professor incentivou a interação com os colegas e a observação. 
A18: 1. é intercultural não trazer profissões mais representadas como sendo trabalhos ligados a um seleto grupo: doctors, lawyers, etc; 2. O fato de não ser UM ASTRONAUTA (do gênero masculino); 3. A relação com profissões do futuro e presente, que vai depender de cada cultura.

A24: Apresenta duas línguas diferentes, mesclando português e italiano; Responsabilidade pela apresentação respeitosa por duas culturas e a valorização e respeito para cada uma delas; Valorização da cultura do outro.

Diante desta análise podemos inferir que a abordagem estruturalista é aquela com a qual os cursistas têm maior familiaridade. As Abordagens Intercultural e por Tarefas apresentadas ao longo do minicurso parecem ser pouco conhecidas pelos cursistas, sugerindo que o professor da atualidade ainda baseia suas práticas em conceitos mais tradicionais.

\section{Conclusão}

O objetivo deste artigo foi refletir sobre a formação de professores nos dias de hoje, avaliando a familiaridade dos cursistas com as abordagens de ensino trabalhadas durante o curso "Abordagens de ensino de LE para crianças", quais sejam, abordagem estruturalista, abordagem intercultural e por tarefas.

A partir dos dados coletados e apresentados, foi possível inferir que a formação de professores de línguas estrangeiras ainda é permeada por uma visão estruturalista de ensino, em que o professor transmite o conhecimento e os alunos são convidados a realizar atividades para a prática mecanizada da estrutura que está sendo ensinada/ aprendida.

As abordagens Intercultural e por Tarefas adotadas no projeto "Intercultura nas escolas: o italiano como língua e cultura na rede pública de ensino", com as quais as bolsistas já têm familiaridade e sobre as quais conseguem teorizar, parecem ainda não fazer parte do imaginário dos professores em formação que frequentaram o curso, uma vez que suas respostas se limitavam ao que tinha sido apresentado nos vídeos e nos textos. Tal fato pode indicar que, com o curso, eles foram capazes de reconhecer características da abordagem intercultural e da abordagem por tarefas nas atividades propostas.

Todavia, os resultados apontam que seriam necessários outros cursos ou outras vivências que lhes possibilitassem a análise e a avaliação de atividades como aquelas idealizadas pelas bolsistas para as oficinas de sensibilização voltadas para as crianças. Em outras palavras, pode-se dizer que a formação de professores de línguas da atualidade precisa ser repensada para que abordagens comunicativas do Pós-Método (KUMAVARADIVELU, 2012) deixem de ser só teoria e sejam de fato praticadas em sala de aula. 


\section{Referências}

AMIGUINHO, A. Formação de professores - à procura de projetos institucionais globais. Aprender, Revista da ESE de Portalegre, n. 21, Novembro 1998, p. 34-45.

EAST, M. Task-based language teaching from the teachers' perspective. Amsterdam, The Netherlands: John Benjamins, 2012.

ELLIS, R. Teachers evaluating tasks. In: BYGATE, M. (org.). Domains and directions in the development of TBLT. Amsterdam, The Netherlands: John Benjamins, 2015, pp. 248 -270.

ELLIS, R. The methodology of task-based teaching. Asian EFL Journal, v. 8, n. 3, 2006, p. 19-45.

FONTES, S. M. Um lugar para a cultura. In: CUNHA, M. S.; SANTOS, P. (orgs.). Tópicos em Português LE. Brasília: Editora UnB, 2002.

FREITAS, P. G. Ensinando a ensinar com tarefas comunicativas: um percurso para a formação inicial de professores. In: TREVISOL, J.; SILVA, I. T. (orgs.). Fundamentos e práticas no ensino de línguas. Vol. II. Catu: Bordô-Grená, 2020, p. 55-79.

FREITAS, P. G. Intercultura nas Escolas e na Formação de Professores de Línguas. Línguas\&letras, v. 20, n. 46, 2019, p.126-146.

GARCÍA, C. M. Formação de Professores: para uma mudança educativa. Porto: Porto Editora, 1999.

HARMER, J. How to Teach. Harlow: Longman, 2009.

HOLLIDAY, A. Appropriate methodology and social context. Cambridge: CUP, 1994.

IMBERNÓN, F.; COLÉN, M. T. Los vaivenes de la formación inicial del professorado. Una reforma siempre inacabada. Revista Tendencias Pedagógicas, n. 25, 2014, p. 57-76.

KUMARAVADIVELU, B. The post-method: (E)merging strategies for second/foreign language teaching. In: TESOL Quarterly 28, p. 27-48, 1994. DOI: https://doi.org/10.2307/3587197.

KUMARAVADIVELU, B. Language Teacher Education for a Global Society. New York: Routledge, 2012.

LANDULFO, C.; BARROS, K. Currículo e Formação de Professores de Línguas: por uma perspectiva intercultural. Encontro Internacional de Formação de Professores e Fórum Permanente de Inovação Educacional, v. 10, n. 1, 2017.

LIDDICOAT, A. J., PAPADEMETRE, L., SCARINO A., KOHLER, M. Report on intercultural language learning. Camberra: Commonwealth Department of Education, Science and Training, 2003.

LIDDICOAT, A. J.; SCARINO, A. Intercultural Language Teaching and Learning. Oxford: Blackwell Publishing, 2013.

LONG, M. H.; ROBINSON, P. Focus on form: theory, research and practice. In DOUGHTY, C.; WILLIAMS, J. (orgs.). Focus on form in classroom second language acquisition. Cambridge: Cambridge University Press, 1998, p. 15-41.

MAIA, A. M. B.; RABELLO, E. C. C.; CERVO, I. Z. S.; SANTOS, L. M. M.; PANS, M. I. B. M. Análise comparativa/contrastiva das abordagens gramatical e comunicativa. Revista Desempenho, n. 1, 2002, p. 31-46.

MATTIA, L. ANGELI, A. N. TERRANERA, L. Leo. Roma: Edizioni Lapis, 2017.

MOTLAGH, F. A.; JAFARI, A. S.; YAZDANI, Z. A General Overview of Task-based Language Teaching (TBLT), from Theory to Practice. International Journal of Language and Linguistics Special Issue: Teaching English as a Foreign/Second Language. Vol. 2, No. 5-1, 2014, p. 1-11. DOI: https://doi. org/10.11648/j.ij1l.s.2014020501.11 
NORRIS, J. Thinking and acting programmatically in task-based language teaching. In: BYGATE, M. (org.). Domains and directions in the development of TBLT. Amsterdam: John Benjamins, 2015, p. 27-58.

NUNAN, D. Task-based Learning and Teaching. Cambridge: CUP, 2004.

ROLDÃO, M. D. C. N. Formação de professores e desenvolvimento profissional. Revista de Educação PUC-Campinas, v. 22, n. 2, 8 jun. 2017, p. 191. DOI: https://doi.org/10.24220/2318-0870v22n2a3638

SAMUDA, V.; BYGATE, M. Tasks in Second Language Learning. Palgrave: Macmillan, 2008.

VAN DEN BRANDEN, K. The Role of Teachers in Task Based Language Education. Annual Review of Applied Linguistics, 36, 2016, pp. 164-181. DOI: https://doi.org/10.1017/S0267190515000070

VAN DEN BRANDEN, K. (Ed.). Task-based language education: from theory to practice. Cambridge, UK: Cambridge University Press, 2006.

WILLIS, J. A Framework for Task-Based Learning. Harlow: Longman, 2003.

XAVIER, R. P. Metodologia do ensino de inglês. Florianópolis: LLE/CCE/UFSC, 2012.

Recebido em: 14/06/2021 (versão atualizada: 04/09/2021)

Aprovado em: 17/08/2021 